\title{
Partnership with African Countries: European Society of Gastrointestinal Endoscopy (ESGE) - Position Statement
}

(6)

ESGE

\section{다 (i) $\odot$}

Authors

Cesare Hassan ${ }^{1}$, Lars Aabakken², Alanna Ebigbo ${ }^{3}$, John Gásdal Karstensen ${ }^{4,5}$, Claire Guy ${ }^{6}$, Mario Dinis-Ribeiro ${ }^{7}$, Olivier Le Moine ${ }^{8}$, Peter Vilmann ${ }^{4}$, Thierry Ponchon ${ }^{9}$

\section{Institutions}

1 Endoscopy Unit, Nuovo Regina Margherita Hospital, Rome, Italy

2 Endoscopy, Oslo University Hospital - Rikshospitalet, Oslo, Norway

3 Department of Gastroenterology, Klinikum Augsburg, Augsburg, Germany

4 Gastro Unit, Division of Endoscopy, Copenhagen University Hospital Herlev, Copenhagen, Denmark

5 Gastro Unit, Division of Surgery, Copenhagen University Hospital Hvidovre, Copenhagen, Denmark

6 European Society of Gastrointestinal Endoscopy (ESGE) Secretariat, Hamilton Services GmbH, Munich, Germany

7 CIDES/CINTESIS, Faculty of Medicine, University of Porto, Porto, Portugal

8 Gastroenterology Department, Erasme University Hospital, Brussels, Belgium

9 Gastroenterology and Endoscopy, Edouard Herriot Hospital, Lyon, France

\section{Bibliography}

DOI https://doi.org/10.1055/a-0677-2026 |

Endoscopy International Open 2018; 06: E1247-E1255

(c) Georg Thieme Verlag KG Stuttgart · New York

ISSN 2364-3722

Corresponding author

Cesare Hassan, MD, Endoscopy Unit, Nuovo Regina Margherita Hospital, Via Morosini 30, Rome 00153, Italy

Fax: +39-06-58446533

cesareh@hotmail.com

Appendix e1 - e3

Online content viewable at:

https://doi.org/10.1055/a-0677-2026

\section{RECOMMENDATIONS}

A new objective for the European Society of Gastrointestinal Endoscopy (ESGE) is to develop long-term partnerships with African countries. For this, an International Affairs Working Group (IAWG) was formed.

In conjunction with the World Endoscopy Organization (WEO), ESGE conducted a survey of gastrointestinal (GI) endoscopy in Africa.

Survey results showed that many African countries have few $\mathrm{Gl}$ endoscopy centers with adequate resources. Barriers to the development of endoscopy services include a shortage of endoscopists who have undergone advanced endoscopy training, and a lack of equipment and basic infrastructure.

Diseases related to infectious etiology are more prevalent than neoplastic diseases in Africa. Any development of endoscopy services needs to consider the local prevalence of diseases for which $\mathrm{Gl}$ endoscopy is required, as well as the availability of resources.

The IAWG will initiate a cascade approach to identify and adapt ESGE guidelines for local use. The guidelines will consider the level of resources available for each intervention, as well as cost, infrastructure, and training, and will be approved by consensus of local experts who are representative of different African areas.

Suitable centers in African countries will be identified, and in future will be developed into WEO/ESGE training centers, to provide local training in both basic and advanced endoscopy according to the needs of the area. 


\section{ABBREVIATIONS \\ ESGE European Society of Gastrointestinal Endoscopy \\ GI gastrointestinal \\ IAWG International Affairs Working Group \\ WEO World Endoscopy Organization}

\section{Introduction}

The principal aim of the European Society of Gastrointestinal Endoscopy (ESGE) is the education and training of gastrointestinal (Gl) endoscopy in European countries. GI endoscopy has become critical in highly prevalent conditions, such as upper $\mathrm{Gl}$ bleeding, biliopancreatic diseases, and the prevention and palliation of GI cancer. The use of GI endoscopy has resulted in improved clinical outcomes and savings in economic and human resources [1].

A new objective for ESGE is to develop long-term partnerships with African countries. This initiative may help to address several barriers that currently prevent the optimal development of Gl endoscopy in these countries. In many African countries, Gl endoscopy is available in only a few centers [2]. Although some regions in northern and southern Africa may have sufficient endoscopy resources, most countries in western and sub-Saharan Africa still lag behind $[3,4]$. The main barriers to development of endoscopy are not limited to human factors; lack of equipment and infrastructure, as well as poor water and power supplies, also feature $[5,6]$.

ESGE may help the situation by providing its own educational and training resources. This is likely to be facilitated by successful - albeit sporadic - joint activities between some European and African centers [6]. In this regard, ESGE may also help in the implementation and networking of national and international societies in the African continent. By liaising with industry, ESGE may facilitate training activities and policies specifically dedicated to African countries. In addition, ESGE clinical and technical guidelines may be adapted according to local needs and resource availability.

As most of these goals and challenges are also shared by the World Endoscopy Organization (WEO), an ESGE International Affairs Working Group (IAWG) was established with participation from the WEO. This collaboration between ESGE and WEO will ensure that efforts to address the paucity of resources in Africa are aligned, and that educational and institutional activities are not duplicated.

The initial aims of the newly developed IAWG were:

- to conduct a general survey of endoscopy activity in Africa

- to develop a cascade methodology to adapt the existing ESGE clinical guidelines to resource-sensitive settings

- to identify suitable African centers to implement training activities.
Table 1 Number of survey responses from each country.

\begin{tabular}{|l|c|}
\hline Country & Survey responses, $\mathbf{n}$ \\
\hline Algeria & 1 \\
\hline Burkina Faso & 1 \\
\hline Cameroun & 6 \\
\hline Chad & 1 \\
\hline Democratic Republic of the Congo & 1 \\
\hline Ghana & 1 \\
\hline Ivory Coast & 2 \\
\hline Kenya & 1 \\
\hline Morocco & 1 \\
\hline Mozambique & 1 \\
\hline Nigeria & 2 \\
\hline Senegal & 1 \\
\hline Sudan & 1 \\
\hline Tunisia & 1 \\
\hline Uganda & 1 \\
\hline Total & 22 \\
\hline
\end{tabular}

\section{Survey of the status of endoscopy centers in Africa}

In order to acquire information on the epidemiology of diseases requiring endoscopy in Africa, as well as on the unmet needs or shortages in training, education, technology, and infrastructure, an internet-based survey was developed. The survey included 40 questions and was sent to all possible contacts. Contacts included institutions (e. g. African scientific societies) and individual centers that had been identified from the contact lists of ESGE, WEO, and European national societies with wellknown and long-lasting relationship with African countries (e.g. the French Society of Digestive Endoscopy).

\section{Results of the survey}

Overall, 22 responses were received from 15 different African countries ( $\triangleright$ Table $\mathbf{1}$ ). When multiple responses were received from one country, the average was calculated and this value represented a country perspective. The detailed results of the individual questions are reported in Appendix e1 (available online), and the main results are summarized below.

\section{Epidemiology}

Diseases related to infectious etiology, such as peptic ulcer disease and liver cirrhosis, scored highest for the most prevalent diseases for which GI endoscopy is required in Africa; GI neoplasia and pancreatic diseases received lower scores ( $\mathbf{F i g . 1 a ) . ~}$ This strictly follows the epidemiological pattern of Gl-related infectious diseases in the African countries. According to sero- 
Pancreatitis/pancreatic cancer

Inflammatory bowel diseases

Peptic ulcer disease

Esophagitis/gastritis

Benign esophageal strictures (caustic, Plummer-Vinson)

Lower GI neoplasia

Upper GI neoplasia

Gallstone disease

Infectious diseases (e.g. related to Helicobacter pylori, HIV)

Cirrhosis/portal hypertension/variceal bleeding

Other(s)* (Not including foreign body removal)

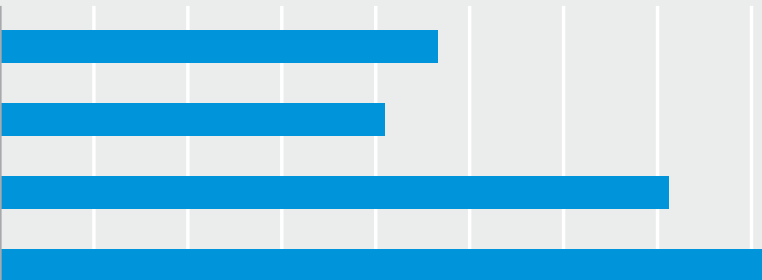

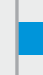
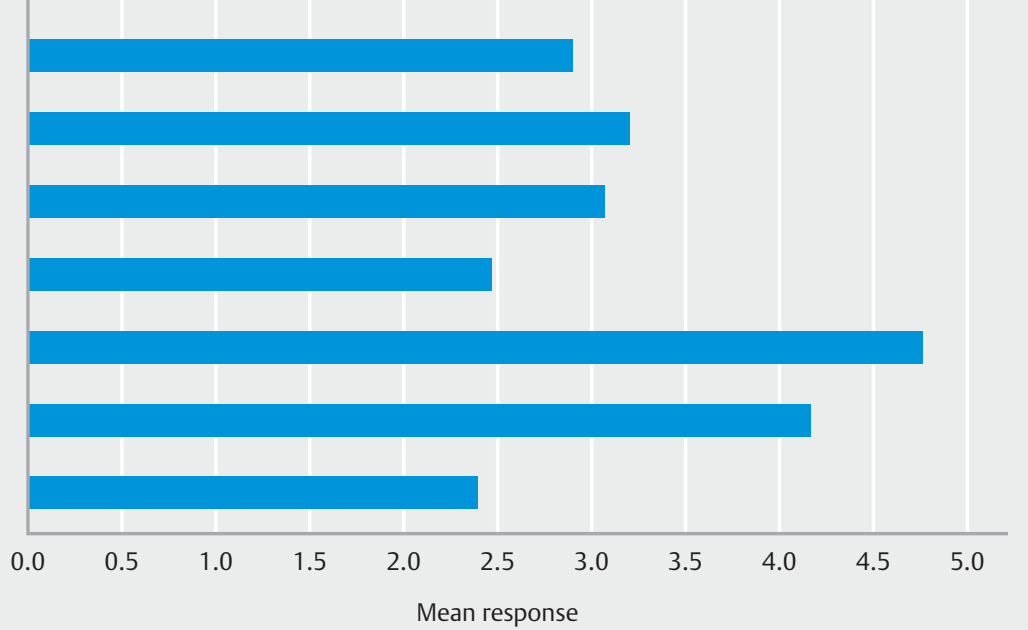

a

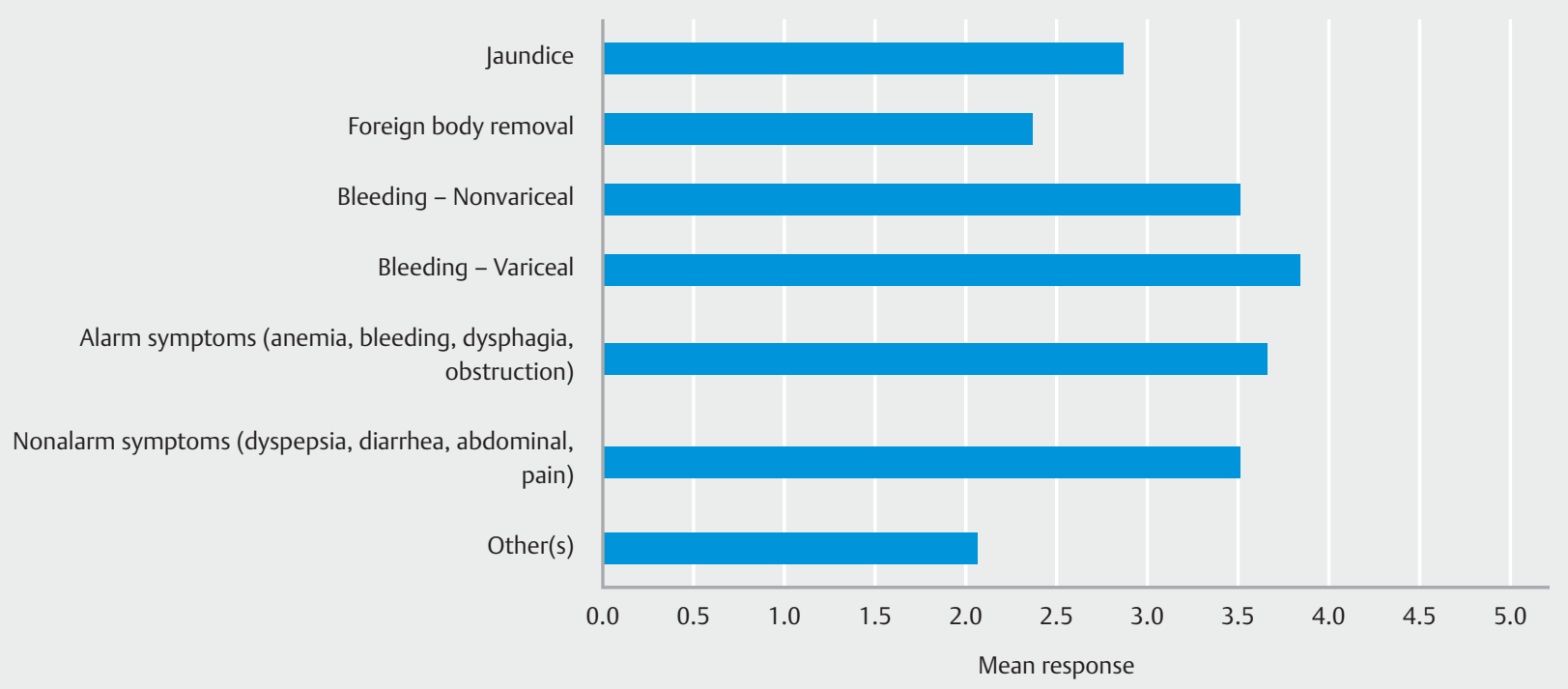

- Fig. 1 Survey responses to the two fundamental questions about endoscopy practice in African countries. a Prevalence of diseases in which gastrointestinal (GI) endoscopy is involved ( $1=$ No prevalence; $5=$ Extremely prevalent). b Main indications for Gl endoscopy $(1=$ Not at all frequent; 5 = Extremely frequent). HIV, human immunodeficiency virus.

logical studies, $61 \%-100 \%$ of the African population is infected with Helicobacter pylori, and the infection seems to be highly prevalent since childhood [7]. Similarly, the prevalence of viral hepatitis in sub-Saharan regions is among the highest in the world, leading to chronic liver disease and hepatocellular carcinoma $[8-10]$. This situation is reflected in the survey results, which identified upper GI bleeding for variceal or nonvariceal bleeding, in addition to other alarm symptoms, as the main indications for Gl endoscopy ( $\bullet$ Fig. 1b). The epidemiology of GI cancer also differs fundamentally from Western countries. For instance, the respective age-standardized annual incidence of gastric, colorectal, and pancreatic cancer is $<5$ per 100000 population in most African regions, representing among the lowest estimates worldwide [11]. This is likely to explain why our survey showed that upper and lower Gl cancers are not quoted among the main indications for $\mathrm{Gl}$ endoscopy in Africa (Appendix e1). 


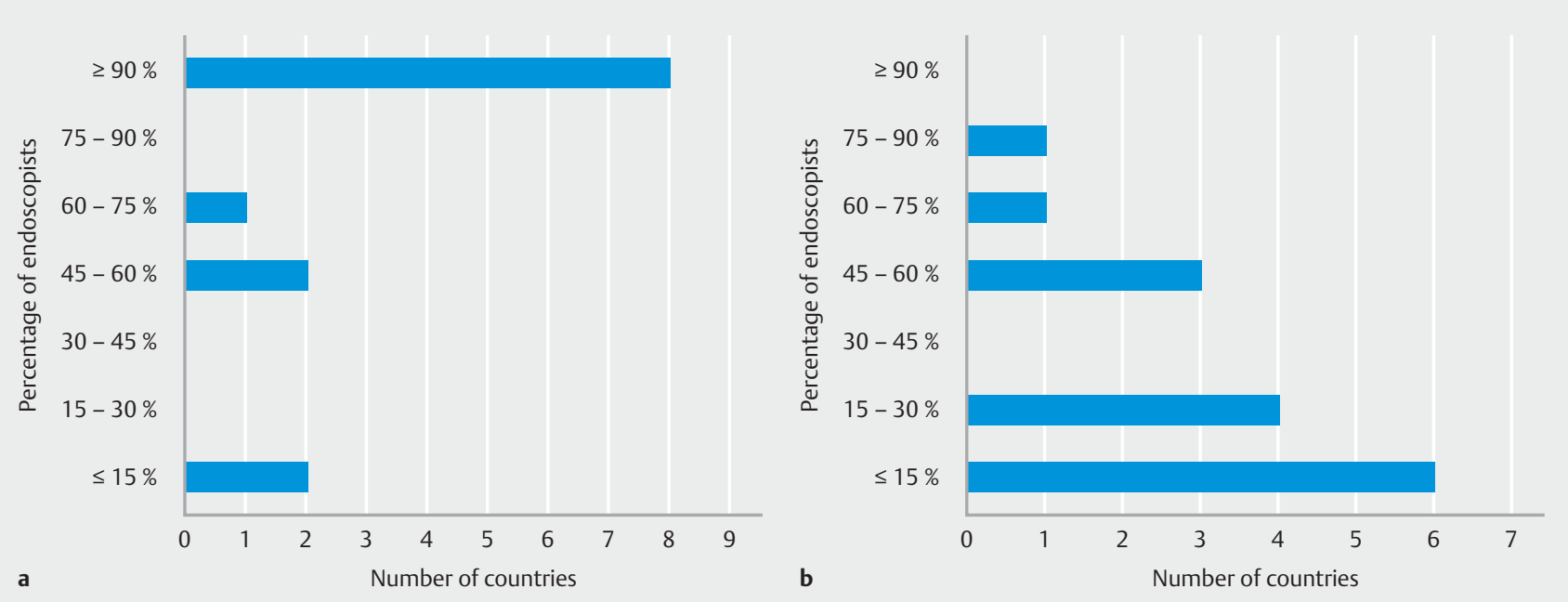

- Fig. 2 Training. Percentage (approximately) of endoscopists who have received different levels of training. a Basic endoscopy only. b Advanced endoscopy.

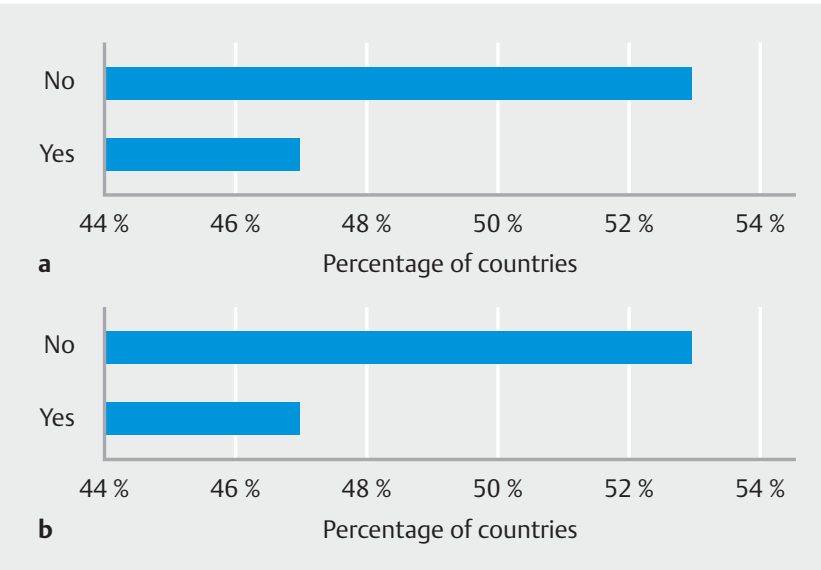

Fig. 3 Availability of endoscopy training centers. a Academic. b Nonacademic.

\section{Training and national societies}

Adequate training of endoscopists can only take place in functional and adequately equipped endoscopy centers. Although it is evident that such endoscopy training centers are lacking, the extent of this shortage is unclear because accurate and comprehensive data are not available. Proper and adequate training of endoscopists would improve the quality of endoscopy services offered in African countries.

The results of the survey showed that most endoscopists from the participating countries undergo some form of training, although the type of training received was not specified. However, in order to differentiate further, participants were asked to state what percentage of endoscopists had received training in basic (i.e. upper and lower Gl endoscopy) and advanced (i.e. endoscopic retrograde cholangiopancreatography, endoscopic ultrasound, therapeutic procedures) endoscopy ( $\vee$ Fig.2). In 8 out of the 13 countries that responded to this

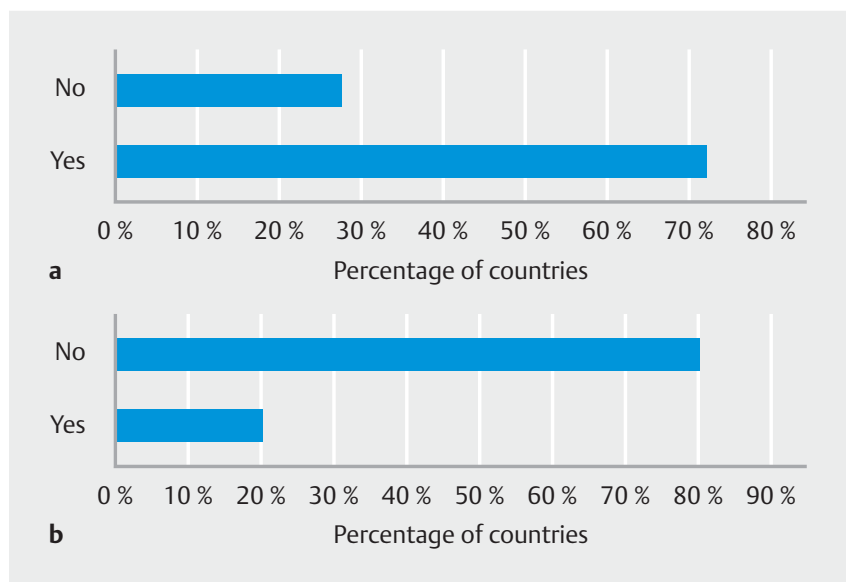

- Fig. 4 Existence of national societies. a National society of gastroenterology. b National society of endoscopy?'

question, the vast majority of endoscopists ( $\geq 90 \%$ ) receive training in basic endoscopy only. However, for advanced endoscopy training, the opposite is the case, with participants in 10 out of the 15 countries stating that fewer than $30 \%$ of endoscopists had received training in advanced endoscopy.

Furthermore, training centers in academic and nonacademic institutions exist in only about half of the participating countries, implying that the other half do not have any formal training centers ( $\mathbf{F i g} \mathbf{3}$ )

The coordination of training facilities and training programs could well be a function for professional gastroenterology and endoscopy societies. Although national gastroenterology societies exist in the majority of the countries that participated in the survey (12/15), only 3 out of the 15 countries (20\%)Morocco, Ivory Coast, and Burkina Faso - have a national endoscopy society ( $\triangleright$ Fig.4). There may be various reasons why most African countries do not have a professional endoscopy society. However, such societies would help focus on the problems and 

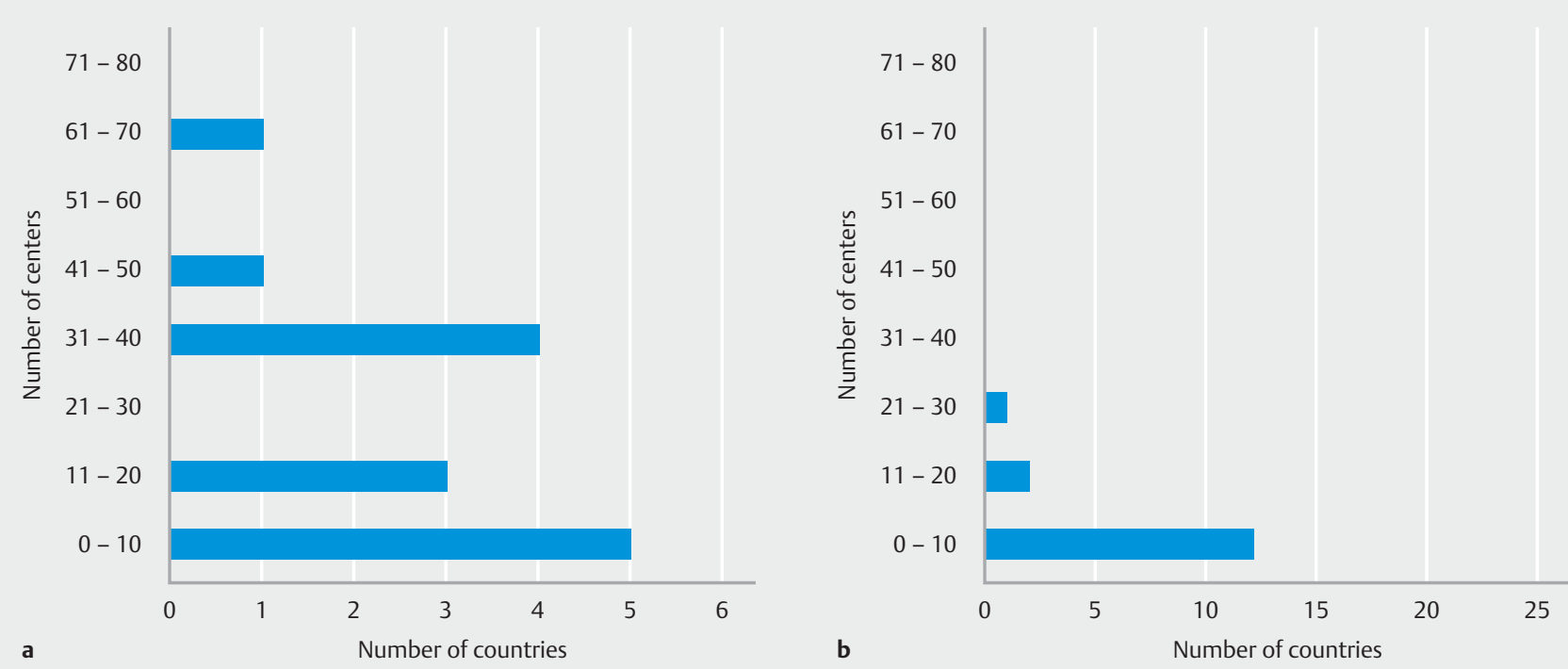

- Fig. 5 Gastrointestinal endoscopy centers providing basic and emergency endoscopy, expressed as estimate of number of centers per country. a Basic endoscopy. $\mathbf{b}$ Emergency endoscopy.

Therapeutic endoscopy centers with anesthesiologist availability

Therapeutic endoscopy centers with fluorosocopy available

Endoscopy centres
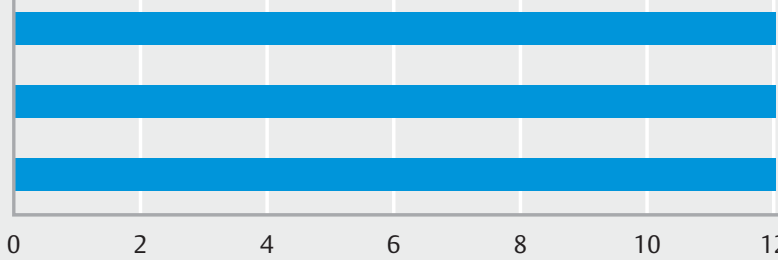

2

4

6

8

10

12

14

a

Number of countries

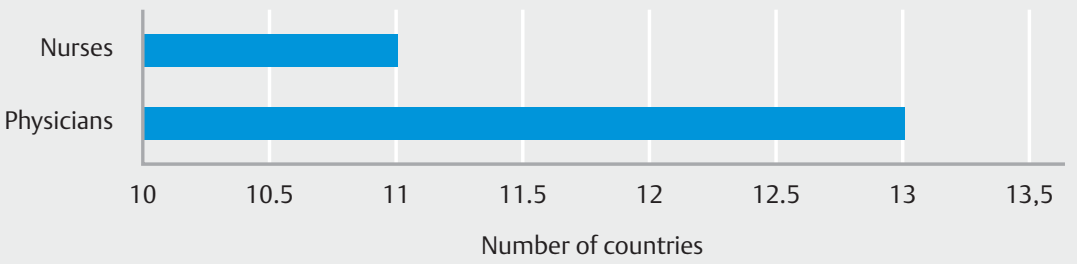

b

Number of countries

- Fig. 6 Shortages of gastrointestinal (GI) endoscopy resources. a GI endoscopy centers. b GI endoscopy personnel.

shortcomings that currently hinder the development of endoscopy in these countries. In addition, a national endoscopy society would be more effective in attracting funds for training centers, which might improve the quality and availability of endoscopy services being offered in these countries. Of note, according to our survey, Gl endoscopy is mostly performed by gastroenterologists, while the contribution, if any, by nonmedical personnel, such as technicians or nurses, is limited (Appendix e1).

Even though the results described in this section do not specify the exact definition of training or the contents of the endoscopy training programs that currently exist, they offer sufficient data to illustrate the difficult situation facing endoscopists in most African countries, especially with regard to training and acquisition of skills in advanced endoscopy procedures. Furthermore, there may be a need to establish endoscopy societies in African countries in order to create a stronger lobby group to support the interests of endoscopists.

\section{Shortage of medical and nonmedical personnel}

In order to secure an adequate medical service, a sufficient density of medical doctors is required. While the density of medical doctors ranges from 1286 to 6645 physicians per 1 million inhabitants in Europe, and 2554 in the USA, the density in African countries is radically lower, ranging from 14 to 1192 physicians per 1 million population [12]. This difference implies a general limitation of medical services in most Africa countries. Similarly, an appropriate number of properly trained 


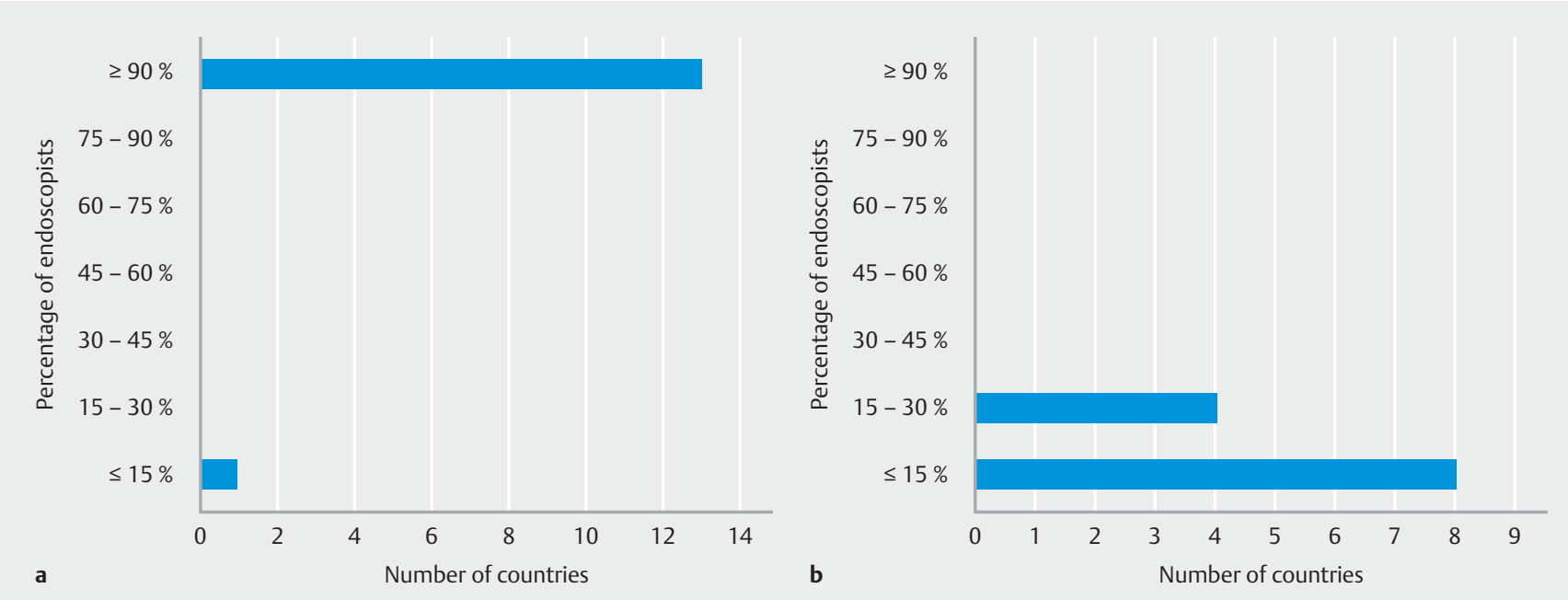

- Fig. 7 Percentage of endoscopists performing endoscopic procedures. a Diagnostic procedures. $\mathbf{b}$ Therapeutic procedures (endoscopic mucosal resection, endoscopic retrograde cholangiopancreatography, dilation, stenting).

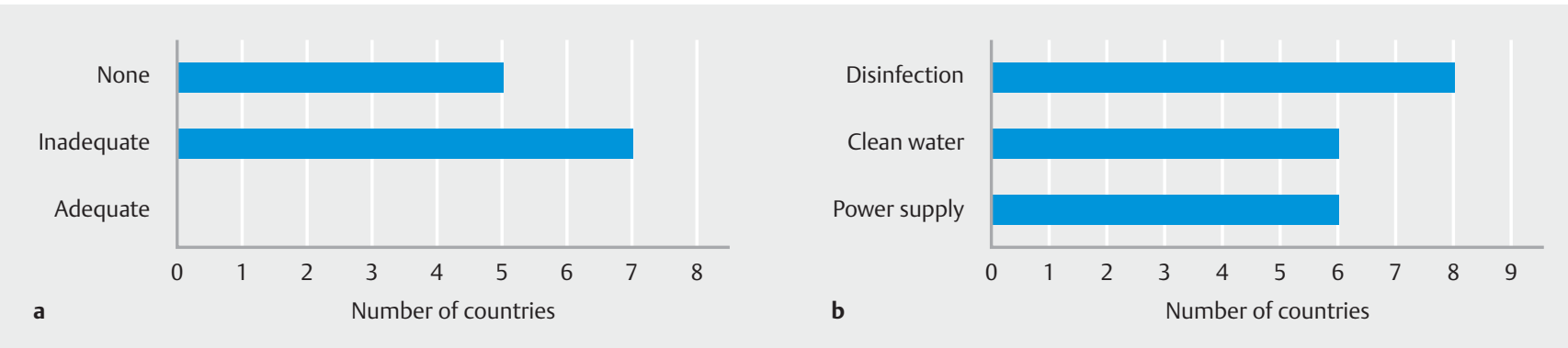

Fig. 8 Reprocessing and basic infrastructure. a Availability of automatic disinfection per country. b Lack of basic infrastructure/resources.

endoscopists is essential to maintain a sufficient endoscopy service $[13,14]$. This lack of physicians is reflected in the waiting time for emergency endoscopy, which in urbanized populations in west Africa is at least 1 day, but can be several days and even up to weeks [5]. Our survey expands on such trends in GI endoscopy. First, it showed that the number of available endoscopy centers performing basic endoscopy (i.e. upper and lower $\mathrm{Gl}$ endoscopy) is low in the majority of the countries ( $>$ Fig.5). Furthermore, the number of centers performing more advanced endoscopy, such as biliopancreatic endoscopy, is also low in the majority of countries, according to the scores given in the survey.

In keeping with these results, most respondents complained of a shortage of both endoscopy centers offering any level of procedure, and of medical personnel in their country ( Fig.6).

We found that, although almost every endoscopist performs routine diagnostic procedures, in two-thirds of the countries included in our survey, less than $15 \%$ of endoscopists carry out therapeutic procedures ( $\triangleright$ Fig. 7 ). Efforts have been made to increase the number of doctors with endoscopy competences; however, the limitations of endoscopy personnel and the level of training remain unaffected $[15,16]$.
In addition to personnel limitations, the endoscopic equipment may also affect the endoscopy medical service. In our survey, we asked the participants whether the number of endoscopes was adequate. While the availability of gastroscopes is considered to be acceptable in over half of the countries, the number of duodenoscopes is only adequate in $20 \%$ of the countries that responded to the survey. Adequate automatic disinfection of endoscopic equipment is not present in any of the included countries, and most reprocessing is performed manually. Furthermore, only minor repairs and maintenance can be undertaken locally. Most countries also complained of a lack of adequate infrastructure, such as clean water and reliable electricity ( $\mathbf{F i g . 8 )}$.

\section{Limitations of the survey}

The main limitation of this survey is the relatively small number of replies received, despite ESGE using multiple channels to spread the invitation. This may limit the generalizability of these data to areas that were not covered. However, this may also be a proxy for a more scattered distribution of endoscopy centers in African countries. Future ESGE activities should maximize the cooperation between ESGE and African endoscopy centers, in order to minimize such bias. 
- Table 2 Main steps of the cascade approach applied to the European Society of Gastrointestinal Endoscopy guidelines.

\section{Cascade steps}

1. Selection of suitable ESGE guidelines
- Factors to be considered:

- Epidemiology

- Dependence of the recommended interventions on the level of available resources

- Availability of local expert to substantiate the proposal of alternative strategies

2. Selection of the working group

3. Definition of the level of resources required for each intervention

- Members of the IAWG

- Author(s) representative of the original ESGE guideline

- Local experts

- Others
4. Adaptation of intervention according to the level of resources
- Basic level Core resources or fundamental services absolutely necessary for an endoscopy care system to function. By definition, a healthcare system lacking any basic-level resource would be unable to provide endoscopic services to its patient population. It includes diagnostic procedures (gastroscopy and colonoscopy), as well as fundamental monitoring abilities (blood pressure, basic blood biochemistry).

- Limited level Second-tier resources or services that produce major improvements in outcome, such as increased survival, but that are attainable with limited financial means and modest infrastructure. It includes minor endoscopic procedures to improve major clinical outcomes (i. e. sclerotherapy/adrenaline injection, band ligation, plasma expanders, basic surgical interventions).

- Enhanced level Third-tier resources or services that are optional but important. Enhanced-level resources may produce minor improvements in outcome but increase the number and quality of therapeutic options. Most procedures that improve clinical outcome are available (i. e. biliopancreatic endoscopy, electrosurgical unit, polypectomy/mucosectomy, anesthesia back-up).

- Maximal level High-level resources or services that may be used in some high-resource countries or be recommended in guidelines that assume unlimited resources. To be useful, maximal-level resources typically depend on the existence and functionality of all lower-level resources.

Factors to be considered:

- Cost

- Endoscopy

- Other technology

- Economic

- Infrastructure

- Organizational

- Professional

- Training

Local experts who are representative of different African areas (economic, geographical, level of resources, etc.)

5. Modified Delphi process

ESGE, European Society of Gastrointestinal Endoscopy; IAWG, International Affairs Working Group.

\section{Cascade methodology}

The majority of the countries reported a lack of local guidelines (Appendix e1). In addition, the same countries also considered international guidelines to be potentially suitable for African countries, pending adaptation to reflect available local resources. For this reason, ESGE decided to adapt existing guidelines to the local situation by using a cascade approach [17].

- Table 2 describes the steps that will be involved in the cascade approach. The first step will involve the review of individual ESGE guidelines to select recommendations that are appropriate for African countries. Selection will depend on critical factors, as shown in $>$ Table 2 . The second step will be the creation of a working group for each guideline, which will include international and local experts. The third step aims to define the level of resources required for each individual intervention recommended by the specific guideline. Four levels of resource availability will be used ( $\triangleright$ Table2) [18], ranging from basic, when only minimal resources are available, to enhanced or maximal, when all the important resources are available. The fourth step will involve the adaptation of existing guideline recommendations to the different levels of resource availability. This process will be performed by the working group, and several resource types, such as human, technological, economic, 
and financial, will be considered ( $\triangleright$ Table 2 ). From this process, alternative (i. e. adapted) recommendations for each level of resource will be generated. The fifth and final step will employ an internet-based platform to achieve consensus on recommendations using a modified Delphi agreement process [19]. This step will involve local experts representative of both well-developed and least-developed areas of Africa, and is an important element of partnership development.

For the revision and publication processes, the adapted guidelines generated from this cascade process will follow the same methodology as for original guidelines [20].

\section{WEO/ESGE training centers}

In order to facilitate the development of GI endoscopy and related training, ESGE in conjunction with the WEO will identify African centers that-given the appropriate support-have the potential to provide local $\mathrm{Gl}$ endoscopists with training in both basic and advanced procedures, according to the main indications for endoscopy in the local area. We will start with a single center in order to explore the strategies that are most effective in addressing the needs and assessing the effects of training. In addition, WEO and ESGE will offer various forms of training support and other outreach activities to such centers. The training centers will need to meet certain criteria in order to demonstrate their ability to carry out the activities, including sustainability (Appendix e2, Appendix Table e3, available online).

\section{Summary}

Our survey identified critical barriers to the implementation of $\mathrm{Gl}$ endoscopy in developing areas of Africa, namely a lack of training centers, especially for advanced procedures, and a shortage of medical professionals. When addressing these barriers, the different epidemiology between African and European areas should be taken into account, as the epidemiology of $\mathrm{Gl}$ diseases is skewed toward infectious rather than neoplastic diseases. The identification of local WEO/ESGE training centers may help facilitate future development in endoscopy. Our survey also identified the need for Gl endoscopy guidelines in several African countries, which should include current guidelines that have been adapted according to the level of resources available locally. For this reason, we created a specific methodology for the development and implementation of adapted ESGE guidelines in resource-sensitive areas.

\section{Disclaimer}

ESGE position statements and guidelines represent a consensus of best practice based on the available evidence at the time of preparation. They may not apply in all situations and should be interpreted in the light of specific clinical situations and resource availability. Further controlled clinical studies may be needed to clarify aspects of the statements, and revision may be necessary as new data appear. Clinical consideration may justify a course of action at variance to these recommendations. ESGE position statements and guidelines are intended to be an educational device to provide information that may assist endoscopists in providing care to patients. They are not rules and should not be construed as establishing a legal standard of care or as encouraging, advocating, requiring, or discouraging any particular treatment.

\section{Acknowledgments}

ESGE would like to thank the following individuals for their valuable responses to the survey. Abdelmounem Eltayeib Abdo, Constant Assi, Emeka Ayogu Levi, Duduyemi Babatunde, Jalel Boubaker, Mohamed Tayeb Bounnah, Uchenna ljoma, Zahi Ismaili, Dyane Kamto, Wilson Miriti Kiraitu, Henriette Kissi, Olga Machekam, Agnès Malongue, Papasaliou Mbaye, Yunus Miya, Prassad Visnum Modcoicar, Ali Mahamat Moussa, Ghislaine Ngatcha, Dr. Ntounda, Roger Sombie, Paul Talla, Magloire Tchidjo Kenmegnie, Marc Van Gossum.

\section{Competing interests}

None

References

[1] Everhart JE, Ruhl CE. Burden of digestive diseases in the United States part I: overall and upper gastrointestinal diseases. Gastroenterology 2009; 136: $376-386$

[2] Mandeville KL, Krabshuis J, Ladep NG et al. Gastroenterology in developing countries: issues and advances. World J Gastroenterol 2009; 15: $2839-2854$

[3] Asombang AW, Turner-Moss E, Seetharam A et al. Gastroenterology training in a resource-limited setting: Zambia, Southern Africa. World J Gastroenterol 2013; 19: $3996-4000$

[4] Chuks NS. Challenges of gastrointestinal endoscopy in resource-poor countries. In: Pascu O, ed. Gastrointestinal Endoscopy. London: InTechOpen; 2011: ISBN 978-953-307-385-9

[5] Perl D, Leddin D, Bizos D et al. Endoscopic capacity in West Africa. Afr Health Sci 2016; 16: 329-338

[6] Le Moine O, Diouf ML, Mbengue $M$ et al. Creation of a therapeutic digestive endoscopy suite in Senegal: renovation, training and university certification. Results of a Belgian-Senegalese inter-university project. Endoscopy 2012; 44: 177-185

[7] Segal I, Ally R, Mitchell H. Helicobacter pylori - an African perspective. QJM 2001; 94: 561 - 565

[8] Karoney M], Siika AM. Hepatitis C virus (HCV) infection in Africa: a review. Pan Afr Med J 2013; 14: 44

[9] Rao VB, Johari N, du Cros P et al. Hepatitis C seroprevalence and HIV co-infection in sub-Saharan Africa: a systematic review and meta-analysis. Lancet Infect Dis 2015; 15: 819-824

[10] Apata IW, Averhoff F, Pitman J et al. Progress toward prevention of transfusion-transmitted hepatitis B and hepatitis C infection - subSaharan Africa, 2000-2011. MMWR Morb Mortal Wkly Rep 2014; 63: 613-619

[11] International Agency for Research on Cancer. Stomach cancer. Estimated incidence, mortality and prevalence worldwide in 2012. Available from: http://globocan.iarc.fr/old/FactSheets/cancers/stomachnew.asp 
[12] World health Organization. Global Health Observatory (GHO) data. Density of physicians 2017: Available from: http://www.who.int/gho/ health_workforce/physicians_density/en/ Volume 2017

[13] Mandeville KL, Krabshuis J, Ladep NG et al. Gastroenterology in developing countries: issues and advances. World J Gastroenterol 2009; 15: $2839-2854$

[14] Moayyedi P, Tepper J, Hilsden R et al. International comparisons of manpower in gastroenterology. Am J Gastroenterol 2007; 102: 478 481

[15] Perl D, Leddin D, Bizos D et al. Endoscopic capacity in West Africa. Afr Health Sci 2016; 16: 329-338

[16] Wilhelm TJ, Mothes H, Chiwewe D et al. Gastrointestinal endoscopy in a low budget context: delegating EGD to non-physician clinicians in Malawi can be feasible and safe. Endoscopy 2012; 44: 174-176
[17] Sloan FA, Gelband H, eds. Cancer control opportunities in low- and middle-income countries. Institute of Medicine (US) Committee on Cancer Control in Low- and Middle-Income Countries Washington (DC): National Academies Press (US); 2007

[18] Sloan FA, Gelband H , eds. Cancer control opportunities in low- and middle-income countries. Washington (DC): National Academies Press (US); 2007

[19] Milholland AV, Wheeler SG, Heieck JJ. Medical assessment by a Delphi group opinion technic. N Engl J Med 1973; 288: 1272-1275

[20] Dumonceau JM, Hassan C, Riphaus A et al. European Society of Gastrointestinal Endoscopy (ESGE) Guideline Development Policy. Endoscopy 2012; 44: 626-629 